\title{
Perspectivas da produção científica sobre epistemologia da Ciência da Informação no âmbito do ENANCIB
}

\author{
Perspectives of scientific production on epistemology of Information Science in the frame- \\ work of ENANCIB
}

\author{
Alexander William Azevedo \\ Doutorando em Ciência da Informação \\ Universidade Federal de Pernambuco \\ azevedo.aw@gmail.com
}

\section{Resumo}

A pesquisa vislumbrou analisar as publicações no escopo da epistemologia da Ciência da Informação, por meio dos estudos da literatura especializada produzida no Encontro Nacional de Pesquisa em Ciência da Informação (ENANCIB), no período de 2014 a 2016. Buscou-se verificar a consolidação do tema nas comunicações no grupo de trabalho Estudos Históricos e Epistemologia da Ciência da Informação (GT1) do evento científico, abrangendo os 67 trabalhos distribuídos nas três edições compreendidas pela pesquisa. Nesse sentido, a pesquisa possui uma abordagem exploratória e descritiva, por se tratar de um estudo de natureza bibliográfica, na qual se utilizou de documentos salvaguardados nos anais do ENANCIB. O principal resultado demonstra que há um crescimento na produção científica sobre epistemologia da Ciência da Informação no ENANCIB, indicando um fortalecimento o pensamento científico no Brasil.

\section{Palavras-chave}

Comunicação científica. . ENANCIB. Epistemologia da Ciência da Informação. Produção científica.

\begin{abstract}
The research aimed to analyze the publications in the scope of the epistemology of Information Science through studies of specialized literature produced at the National Meeting of Research in Information Science (ENANCIB), from 2014 to 2016. We sought to verify the consolidation of the theme. in the communications in the working group: Historical Studies and Epistemology of Information Science (WG1) of the scientific event, covering the 67 works distributed in the three editions covered by the research. In this sense, the research has an exploratory and descriptive approach, because it is a bibliography study, which used documents safeguarded in the annals of ENANCIB. The main result shows that there is a growth in scientific production on Information Science epistemology in ENANCIB, indicating a strengthening of scientific thinking in Brazil.
\end{abstract}

\section{Keywords}

Scientific communication. ENANCIB. Epistemology of Information Science. Scientific production.

\section{INTRODUÇÃO}

A busca pela condescendência da Ciência da Informação, na sociedade contemporânea, tendo como pressuposto a concepção epistemológica de uma ciência que está em estado permanente de construção de um novo espírito científico paradigmático, exige de sua 
comunidade científica análises complexas para tratar de explicar os efeitos do pensamento científico na esfera da pesquisa.

$\mathrm{Na}$ estrutura de uma nova ciência com seus pilares na interdisciplinaridade, a Ciência da Informação apropriou-se de conceitos advindos de diferentes áreas do conhecimento, que fundamentaram seu arcabouço teórico e metodológico, orientando suas atividades científicas. (BASI; SILVEIRA, 2007).

A partir do pensamento científico na Ciência da Informação, desenvolveram-se as abordagens epistemológicas na área, como é possível observar no historicismo de Hjørland (1998), e os paradigmas de Capurro (2003), entre outros pesquisadores, que contribuíram de forma efetiva com os elementos sociais na formação das pesquisas sobre os fenômenos informacionais presentes no conhecimento científico da Ciência da Informação.

A problemática que se configura, nesse sentido, é se a Ciência da Informação apresenta um dinamismo nas comunicações científicas, pela qual se segue a questão sobre os estudos de pesquisadores dedicados à reflexão histórica, teórica e epistemológica sobre a área. A presente pesquisa não responde a todas possíveis indagações que podem ser levantadas, limitando-se a observarmos para um recorte da literatura especializada em busca das discussões sobre a produção científica nesta temática.

Neste prisma, a proposta foi de reunir elementos que serviram de base teórica para uma análise sobre a história e epistemologia da Ciência da Informação. Para isso, fez necessário questionar-se sobre a ciência e o pensamento científico, considerando que esses questionamentos podem ser interpretados de várias maneiras, dependendo de onde, como e por quem esteja observando.

A pesquisa epistemológica nos remete a um campo da filosofia conhecida como filosofia da ciência, que se trata da vertente científica que investiga os conceitos e leis que regem uma determinada ciência, com a finalidade de fundamentar na teoria o que é realizado na prática, além de refletir sobre pensamento científico e seus estatutos.

Deste modo, buscou-se analisar os estudos sobre história e epistemologia da Ciência da Informação por meio das comunicações no Encontro Nacional de Pesquisa em Ciência da Informação (ENANCIB), fórum realizado desde 1994 que congrega pesquisadores no contexto brasileiro, no qual apresentam suas pesquisas já concluídas ou em andamento, distribuídas conforme temáticas de interesse em 11 (onze) grupos de trabalho (GT). O ENANCIB é um evento anualmente organizado pela sociedade científica de pesquisadores da área, denominada de Associação Nacional de Pesquisa em Ciência da Informação (ANCIB).

A produção do conhecimento científico no campo da Ciência da Informação no cenário brasileiro se concentra nos programas de pós-graduação de universidades públicas e privadas, como também em entidade governamental como Instituto Brasileiro de Informação em Ciência e Tecnologia (IBICT), que mantém convênio com programas de pós-graduação da área (FREIRE, 2008).

Segundo Souza (2012, p. 62), a Ciência da Informação foi desenvolvida com base no avanço e no amadurecimento da Biblioteconomia e nas questões a ela relacionadas, conforme constatado nos programas de pós-graduação, nos eventos acadêmicos e nas publicações científicas, na qual o "[...] campo vem revelando um crescente processo de institucionalização, notadamente, com a ampliação da pesquisa e da pós-graduação.".

Optou-se no estudo abordar a literatura especializada produzida nas comunicações científicas apresentadas nos anais do ENANCIB, especificamente no Grupo de Trabalho 1 (GT1), que contempla a temática "Estudos Históricos e Epistemológicos da Informação", cujas pesquisas tomamos como instrumento para investigação, que possibilitou examinar as 
questões epistemológicas da Ciência da Informação, por meio de uma linha evolutiva no pensamento científico histórico.

Objetivou-se, por meio deste estudo, apresentar um extrato dos trabalhos apresentados no GT1, no período 2014 a 2016, buscando verificar os principais temas de pesquisas a partir de palavras-chaves; identificando os pesquisadores e as instituições que versam seus estudos aos desdobramentos epistemológicos da Ciência da Informação, compreendendo e contextualizando a constituição da área através das comunicações do GT1 do ENANCIB.

\section{EPISTEMOLOGIA NA CIÊNCIA DA INFORMAÇÃO}

As reflexões em torno dos estudos epistemológicos apresentam diferenças em seus aspectos teóricos e metodológicos, que possibilitam o desenvolvimento e o amadurecimento de pensamentos científicos que, segundo Francelin (2005), as ramificações e os conceitos do que venha a ser epistemologia está longe de qualquer tipo de facilidade aparente de compreensão.

A epistemologia em seus postulados se preocupa com a relação entre a ciência, sociedade e as instituições científicas, inferindo na produção e organização da ciência, além de perscrutar, etimologicamente, em seu significado de discurso (logos) sobre a ciência (episteme), com a proposta de refletir os princípios estruturais de reorganização ou reencaminhamento de uma determinada disciplina em seu trajeto científico, na busca de delimitar um campo de estudo (JAPIASSU, 1986).

Destarte, a epistemologia à qual se refere Japiassu (1986) tem o ofício de refletir não somente sobre uma ciência feita e acabada, mas sobre o processo de desenvolvimento científico corroborando de forma interdisciplinar com várias ciências.

O conjunto de fenômenos em múltiplas relações, que a epistemologia aborda de acordo com o contexto e parcialidade observacional, tanto nas esferas filosóficas, ideológicas e culturais, surge o que se conhece como: a epistemologia histórica de Gaston Bachelard; a epistemologia genética de Jean Piaget; a epistemologia arqueológica de Michel Foucault; e a epistemologia racionalista crítica de Sir Karl Popper (JAPIASSU, 1986).

Para Bachelard (1978), o pensamento científico contemporâneo ocorre nas relações entre a realidade e a racionalidade, entre que "o mundo e o espírito" encaminham a refletir sobre as crises do conhecimento científico que obrigam a reclassificação do realismo por meio das relações de observações.

Neste processo, Morin (1997) destaca que não há conhecimento sem autoconhecimento, ou seja, o desenvolvimento do pensamento científico é complexo, pois sua construção e desconstrução estão concatenadas com suas bases paradigmáticas. Uma discussão exemplificadora que podemos examinar a complexidade está na origem da vida humana, que é uma indagação amplamente conferenciada por décadas, na qual a teoria evolucionista de Charles Darwin traduz uma quebra de paradigma com a teoria criacionista apresentada pela teologia judaica cristã.

Para Kuhn (2005, p. 13), os paradigmas são “[...] realizações científicas universalmente reconhecidas que, durante algum tempo, fornecem problemas e soluções modelares para uma comunidade de praticantes de uma ciência.". O desenvolvimento pensamento científico não foi marcada apenas pelo crescimento teórico e metodológico, mas, também, pelas inúmeras transformações e rupturas de paradigmas que possibilitam a cedência de uma teoria para outra. 
Em síntese, o paradigma pode ser definido como um conjunto de regras, normas, crenças e teorias que subsidia um modelo de problema e/ou solução aceitável por um determinado período a uma comunidade ou disciplina científica (FRANCELIN, 2005).

Neste período em que os problemas afloram e um conjunto de possíveis soluções era apresentado metodologicamente ou sanado por paradigmas, foi epitetado por Kuhn (2005) como ciência normal, que significava resolver quebra-cabeças. Quando o paradigma é aceito por uma determinada comunidade científica, também adquire os problemas e os critérios para resolvê-los.

Ao discutir a epistemologia pautada na Ciência da Informação, não é uma tarefa fácil identificar as alterações no tempo histórico que marcou o surgimento da área, sua interdisciplinaridade com outras áreas do conhecimento na tentativa de explicar os fenômenos informacionais (AZEVEDO, 2009).

Toffler (2014) explana que a humanidade vivenciou até a contemporaneidade, três grandes eventos históricos denominados pelo autor como "ondas", sendo a "primeira onda" caracterizada pela revolução agrícola, a "segunda onda" marcada pelo acesso à sociedade industrial, com o êxodo rural. Por fim a "terceira onda", isto é, a revolução técnica-científica pós-industrial, ou era da informação, que se completa nos dias de hoje, e está estruturado pelo tempo acelerado na rotina dos indivíduos, pela ciência moderna e a pela circulação do conhecimento.

A ciência moderna para Wersig (1993) foi um produto gerado na Segunda Guerra Mundial, na qual alterou a função do conhecimento na sociedade.

A literatura especializada que trata da história da Ciência da Informação traça sua origem no conhecimento interdisciplinar e na informação científica e social em consonância com período que ocorreu a explosão da informação. Gerou-se nesse cenário um grande volume de informações com as atividades da produção científica durante a Segunda Guerra Mundial, necessitando da organização do conhecimento acumulado, bem com o desenvolvimento de tecnologia para recuperação e uso da informação.

Desta forma, a maturidade e o progresso científico da Ciência da Informação estão relacionados aos seus paradigmas que sua comunidade científica questiona e investiga, devido à dinâmica dos conceitos, teorias e metodologias informacionais.

Capurro (2003), influenciado com a epistemologia dos três mundos ${ }^{1}$ de Sir Karl Popper (1975), formulou a sua tese que a Ciência da Informação nasceu a partir de três paradigmas: físico, cognitivo e o social. O paradigma físico empreende o objeto físico que o emissor transmite ao receptor, desconsiderando o papel ativo do usuário (sujeito cognoscente), no processo de recuperação da informação, bem como em todo processo informativo e comunicativo em geral. Já o paradigma cognitivo centra no sujeito individual e cognoscente, que são os modelos mentais transformados durante o processo informacional. Por fim, o paradigma social que se refere à informação não apenas como uma mensagem (paradigma físico) processada a um nível cognitivo (paradigma cognitivo), mas na sua relação com o contexto na qual a informação pode ter a peculiaridade de ser importante para um grupo ou para um indivíduo. (CAPURRO, 2003).

\footnotetext{
${ }^{1}$ Popper (1972) apresentou em seu esquema ontológico três mundos, sendo o primeiro mundo físico e material; o segundo mundo constituído do conhecimento humano subjetivo ou dos estados mentais; e o terceiro mundo do conhecimento objetivo, formado pelos produtos da mente humana como gravados nas línguas, nas artes, nas ciências, nas tecnologias em todos os artefatos humanos e na sua totalidade implícita nos objetos elaborados pelo homem, como documentos.
} 
A partir dos paradigmas de Capurro (2003), pode-se descrever que a Ciência da Informação, efetivamente, preocupa-se tanto com a pesquisa, como a prática profissional relativa à organização, à gestão, ao tratamento, à recuperação e ao uso da informação e do conhecimento em contextos sociais, institucionais e individuais (KOBASHI; TÁLAMO, 2003). Assim, a Ciência da Informação, segundo Wersig (1993), pode ser entendida como ciência nova que concerne às necessidades de conhecer, resolver ou lidar com problemas informacionais.

\section{CIÊNCIA DA INFORMAÇÃO: PERCURSO HISTÓRICO DE UMA NOVA CIÊNCIA}

A gênese da Ciência da Informação tem sua constituição relacionada à interdisciplinaridade na formação de seu objeto, ou seja, a informação que é uma questão amplamente discutida na literatura especializada nacional e estrangeira sobre múltiplos enfoques. Para Braman (2006), a informação na sociedade moderna tem desempenhado a função na produção e no processo de recursos de informação decisórios.

No percurso história da sociedade, podemos verificar que as práticas de cunho científico foram criadas e estruturadas com o objetivo de organizar, tratar e recuperar informação, com destaque para Biblioteconomia, Bibliografia, Arquivologia, Documentação e Ciência da Informação.

A Biblioteconomia é notoriamente considerada a mais antiga entre as ciências mencionadas, visto que desde o primórdio da escrita estabeleceu em reprodução, buscando-se técnicas para organização em forma de acervos.

Já Bibliografia teve sua origem atrelada às técnicas biblioteconômicas, com objetivos claros de retratar o conteúdo dos documentos organizados, que no final do século XIX, devidos aos avanços nas técnicas bibliográficas e o surgimento dos periódicos científicos, a bibliografia contribuiu para o desenvolvimento da Documentação na Europa (NUNES, 2009).

Logo a Arquivologia também teve ligações identitárias com a Biblioteconomia, desde o surgimento dos suportes escritos do conhecimento humano que se gerou técnicas e procedimentos para organização a fim de preservação e recuperação de suportes documentais (ARAÚJO, 2011).

Para Azevedo (2009), a Documentação se estruturou a partir dos esforços de Paul Otlet e Henri La Fontaine que alicerçaram uma nova ciência, criando ano de 1885, o Instituto Internacional de Biografia (IIB), que décadas depois, em 1937, transformou-se na Federação Internacional de Documentação (FID), com o objetivo subsidiar os estudos e as práticas da Documentação como uma disciplina científica findada nas questões concernentes ao livro e à organização sistemática da documentação em bases internacionais.

Segundo Shera (1980, p. 94), a Documentação foi definida por Paul Otlet como “[...] processo de reunir, classificar e difundir todos os documentos de toda espécie [...]", salientado que ocorreu no contexto que se estende ao final do século XIX e início do século XX, uma cisão entre a Documentação com a Biblioteconomia, na qual, historicamente, teve grandes dificuldades de organizar seu corpus teórico e metodológico, diante do desafio de recuperar informação no período conhecimento como explosão da informação ou explosão do volume da massa documental.

Pesquisadores como Rayward (1997), Mattelart (2002) e Ortega (2007) destacam que a documentação ofereceu elementos para criação de Ciência da Informação, isto porque a combinação de algumas das técnicas da Documentação atreladas às modernas tecnologias 
da informação e comunicação fortaleceu o crescimento e o desenvolvimento desta nova ciência.

Vannevar Bush, uma autoridade no campo da pesquisa científica durante a Segunda Guerra Mundial, nomeado em 1941, pelo presidente Franklin D. Roosevelt, o primeiro diretor do Office of Scientific Research and Development, órgão responsável pela coordenação de pesquisas realizadas em universidades e institutos de pesquisa para o Departamento de Defesa dos Estados Unidos da América (EUA), apontou em seu artigo As We May Think ${ }^{2}$ (como podemos pensar) publicado, em julho de 1945, pela The Atlantic Monthly, a necessidade da evolução tecnológica como uma maneira de enfrentar o problema da complexidade da recuperação da informação.

Com a explosão da informação, também conhecido como explosão documental, por ampliar de forma significativa a produção do conhecimento, emergiu a preocupação dos métodos de organização e tratamento da informação para recuperação automatizada da massa documental, gerando desta forma a Ciência da Informação. (SMITH; TÁLAMO, 2007).

Borko (1968) classifica a Ciência da Informação como uma disciplina científica com bases teóricas na informação, dedicado à melhoria de procedimentos, transmissão e acumulação do conhecimento. Já na concepção de Le Coadic (2004), a Ciência da Informação é uma ciência social que tem a responsabilidade de esclarecer os problemas voltados para o ser social que busca informação.

Diante dessa nova configuração, Shera (1980, p. 98) assenta a Ciência da Informação como "[...] um ramo de pesquisa que toma sua substância, seus métodos e suas técnicas de diversas disciplinas para chegar à compreensão das propriedades, comportamentos e circulação da informação.".

Araújo (2011) constata que a origem da expressão Ciência da Informação esteve ligada a atividades científicas na Inglaterra e nos EUA, nas primeiras décadas do século $X X$, e que, no decorrer do tempo, estes cientistas da informação tomaram duas frentes de organização. A primeira foi a em torno de um evento, a Royal Society's Scientific Information Conference, em 1948, com as primeiras discussões sobre information retrieval. A segunda frente de organização refere-se à fundação do Institute of Information Scientists em 1958 na Inglaterra, que promoveu a International Conference on Scientific Information realizado em Washington/D.C, que é identificada como acontecimento que deu origem à Ciência da Informação (SHERA; CLEVELAND, 1977).

Entretanto, foi durante os anos 1960 que a expressão Ciência da Informação tomou forma e se consolidou em duas conferências realizadas no Georgia Institute of Technology em 1961 e 1962 (AZEVEDO, 2009).

Para Pinheiro (2002), é importante esclarecer que, na visão da antiga União das Repúblicas Socialistas Soviéticas (URSS), a Ciência da Informação foi, inicialmente, confundida com informática, devido à denominação informatik em russo, adotada por Mikhailov, Chernyi e Giliarevsky, em seu artigo e, posteriormente, em livro publicados, respectivamente, em $1966^{3}$ e $1969^{4}$, intitulado "Informática: um novo nome para a teoria da informação

2 BUSH, V. As we may think. Atlantic Monthly, v. 176, 1, p. 101-108, 1945. Disponível em: https://www.theatlantic.com/magazine/archive/1945/07/as-we-may-think/303881/. Acesso em: 18 ago. 2019.

${ }^{3}$ MIKHAILOV, A I., CHERNYI, A. I., GILYAREVSKI, R. S. Informatic, a new name for theory of scientific information. Nauchno -Tekhnicheskaya Informatsiya (Scientific and Technical Information), n. 12, p.35-39, 1966.

${ }^{4}$ MIKHAILOV, A I., CHERNYI, A. I., GILYAREVSKI, R. S. Informatics: its scope and methods. In: FID/RI International Federation for documentation. Study Committee Research on Theoretical Basis of Information. On theoretical problems of Informatics. Moscow: All -Union for Scientific and Technical Information, 1969. 
científica", que destaca o quiproquó em relação à terminologia russa, referente à informação científica, cujo significado não é o mesmo em países ocidentais.

Não fugindo da linha histórica anunciada da Ciência da Informação, é relevante frisar que em 1951 foi estabelecido o termo recuperação da informação por Calvin Mooers, que mais tardar em 1957, no Cranfield Institute of Technology, foram realizados estudos para medir os resultados de um sistema computadorizado de recuperação da informação, introduzindo os coeficientes de recall (revocação) e precision (precisão) em relação a um sistema de indexação. (CAPURRO, 2003; SARACEVIC, 1995).

No contexto brasileiro, a Ciência da Informação teve sua gênese no conhecimento científico com forte ligação à documentação por meio do Instituto Brasileiro de Bibliografia e Documentação (IBBD), que em 1968 promoveu uma série de eventos sobre a Ciência da Informação até sua consolidação definitiva no país com a criação do primeiro mestrado na área em 1970.

Vale ressaltar que a reorganização das atividades de ciência e tecnologia no Brasil, na década de 1970, promoveu que o IBBD passasse a ser denominado de Instituto Brasileiro de Informação em Ciência e Tecnologia (IBICT), permanecendo até os dias atuais.

A consolidação da Ciência da Informação no Brasil, também, está relacionada às atividades da Associação Nacional de Pesquisa e Pós-Graduação em Ciência da Informação (ANCIB), sociedade civil sem fins lucrativos, fundada em junho de 1989, com a finalidade de estimular e promover atividades de ensino e pesquisa em pós-graduação nesta área no Brasil (ANCIB, 2019). A principal atividade da ANCIB é a organização do ENANCIB, fórum que congrega pesquisadores e programas de pós-graduação brasileiros para fins de debates e reflexões de temas especializados da Ciência da Informação.

\section{PERCURSO METODOLÓGICO}

O estudo teve sua investigação desenvolvida com a abordagem de caráter exploratório-descritivo, envolvendo a pesquisa bibliográfica, cujo objetivo foi de explicitar o entendimento sobre epistemologia da Ciência da Informação.

Em relação à abordagem do problema, a pesquisa se caracteriza como qualiquantitativa, considerando o emprego da análise dos conceitos teóricos e metodológicos que caracterizou na ordem qualitativa, e o levantamento dos dados que forneceu um panorama quantitativo da literatura da área (GODOY, 2006).

A abordagem qualitativa além de admitir desvelar os processos sociais, propicia a construção de novas abordagens, revisão e criação de novos conceitos durante a investigação (MINAYO, 2007). Dessa maneira, se buscou na literatura especializada as bases teóricas sobre a Ciência da Informação que ofereceu condições para refletir os aspectos epistemológicos da área. A coleta de dados foi realizada através dos anais do ENANCIB, nas edições realizadas entre 2014 a 2016.

Para alcançar os objetivos propostos, analisaram-se as comunicações apresentadas no GT-1 - Estudos Históricos e Epistemologia da Ciência da Informação, do referido evento científico. Evidenciou-se um extrato dos estudos classificando em variáveis de autoria, título, palavras-chave e instituição, buscando investigar as principais preocupações e os assuntos abordados ao longo das edições.

Sob o ponto de vista dos procedimentos metodológicos, o delineamento do corpus de análise deste estudo foi estruturado em quatro etapas, conforme Figura 1. 
Figura 1 - Etapas da pesquisa.

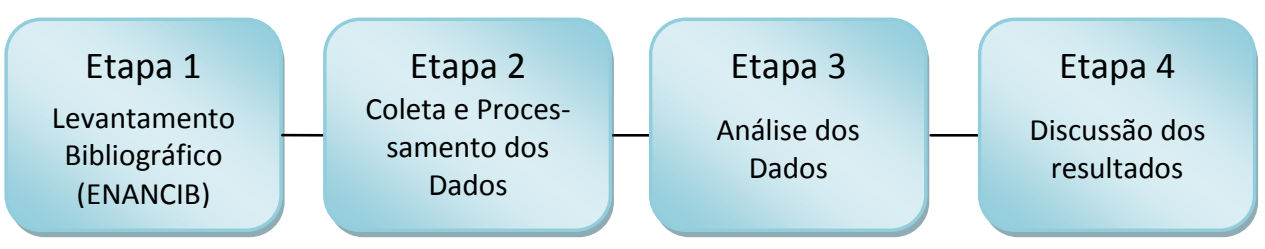

Fonte: Estruturado pelo autor (2019).

O levantamento bibliográfico foi realizado nos anais referentes ao GT-1 - Estudos Históricos e Epistemologia da Ciência da Informação do ENANCIB, no período de 2014 a 2016. Foram utilizados os 67 artigos levantados e pertencentes ao GT1 para análise.

A coleta e processamento dos dados para análise da produção científica divulgada nos ENANCIB permitiu examinar teorias e métodos que norteiam a área. A busca foi efetuada junto ao portal de eventos ANCIB, mediante seleção dos estudos relacionados ao GT1.

O processamento e a análise de dados dos conteúdos dos artigos foram realizados com o auxílio do software Microsoft Office Excelø, para registro das variáveis relacionadas à referência, à autoria, ao título, às palavras-chave, ao vínculo institucional do pesquisador e ao/à ano/edição do ENANCIB.

$\mathrm{Na}$ análise dos resultados, os principais itens investigado em cada artigo foram às palavras-chave, pois sintetizam o assunto pesquisado. Entretanto, averiguaram-se os títulos e os resumos, quando necessário, considerando que o GT1 contém estudos de natureza complexa por se discutir pesquisas que tratam dos paradigmas da Ciência da Informação e seus desdobramentos epistemológicos.

A discussão dos resultados pautou-se nas comunicações analisadas, que teve seus dados revisados, desde a produção científica da edição do ENANCIB de 2014 até as publicações de 2016, podendo verificar as características e o crescente interesse no GT1.

Foi um total de 67 (sessenta e sete) pesquisas apresentadas no grupo temático "Estudos Históricos e Epistemológicos da Informação", no decorrer de três edições do ENANCIB, nas quais se verificou a ocorrência de variações de frequência, conforme ilustrado no Quadro 1.

Quadro 1 - Trabalhos do GT1 publicados nos Anais do ENANCIB (2014-2016)

\begin{tabular}{|l|l|c|}
\hline \multicolumn{1}{|c|}{ Edição } & \multicolumn{1}{|c|}{ Local e ano da realização } & $f(x)$ \\
\hline$X V$ & Belo Horizonte/MG: UFMG, 2014 & 20 \\
\hline$X V I$ & João Pessoa/PB: UFPB, 2015 & 18 \\
\hline$X V I I$ & Salvador/BA: UFBA, 2016 & 29 \\
\hline Total & & 67 \\
\hline
\end{tabular}

Fonte: Estruturado pelo autor (2019).

Na sequência, observa-se, que o XV ENANCIB, realizado em 2014, contou com assuntos diversificados de pesquisas, entre eles, se destacam as abordagens na Arquivologia, seu campo científico e preocupações conceituais que corresponderam aos estudos apresentados.

Na edição XVI ENANCIB em 2015, apesar da variedade de temas apresentados, foi possível constatar a predominância de discussões em torno da interdisciplinaridade e contextos históricos da Ciência da Informação. 
No XVII ENANCIB, realizado em 2016, evidenciaram-se os temas na perspectiva conceitual da Ciência da Informação, distinguindo a própria epistemologia, filosofia e a ética na área. O Quadro 2 apresenta sistematizado, os assuntos mais abordados evidenciados nas palavras-chave dos estudos nas três edições do ENANCIB.

Quadro 2 - Assuntos dos trabalhos do GT1 publicados nos Anais do ENANCIB (2014-2016)

\begin{tabular}{|l|c|l|c|}
\hline \multicolumn{1}{|c|}{ Assunto } & Total & \multicolumn{1}{c|}{ Assunto } & Total \\
\hline Campo Científico da Ciência da Informação & 18 & Produção Científica & 4 \\
\hline Epistemologia da Ciência da Informação & 11 & Regime de Informação & 4 \\
\hline Ética & 9 & Redes Conceituais & 3 \\
\hline Interdisciplinaridade & 8 & Arquivologia & 3 \\
\hline História da Ciência da Informação & 8 & Linguagem & 3 \\
\hline Paradigmas da Ciência da Informação & 7 & Políticas de Informação & 3 \\
\hline $\begin{array}{l}\text { Estudos do Conhecimento em Ciência da } \\
\text { Informação }\end{array}$ & 7 & Teoria da Informação & 3 \\
\hline Filosofia da Informação & 5 & Memória & 3 \\
\hline
\end{tabular}

Fonte: Dados da pesquisa (2019).

As palavras chaves dos artigos somaram um total de 84 (oitenta e quatro) termos, sendo destacados os principais assuntos que representavam em mais de três estudos, distribuímos em 16 categorias de palavras-chaves apresentados no Quadro 2 e consideramos seis termos que seguem na análise de dados. Este procedimento metodológico norteou categorias de assunto de maior incidência das quais discorreremos.

Figura 2 - Nuvem de palavras dos trabalhos do GT1 publicados nos Anais do ENANCIB (2014-2016)

\section{Arquivologia}

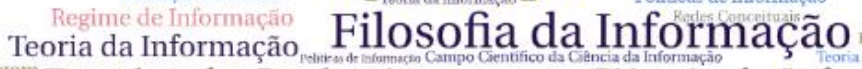

inguagem Estudos do Conhecimento em Ciência da Informação

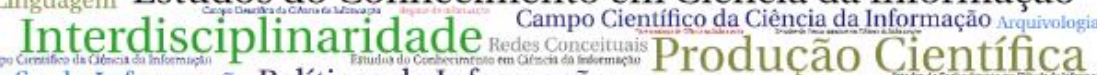

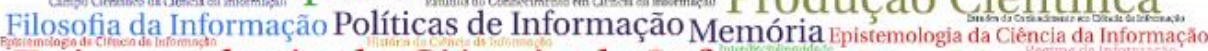

Epistemologia da Ciência da Informaçã̃o Linguagem Ética

Ética Campo Científico da Ciência da Informação

Ética História da Ciência da Informação Memória

Ética Pararadigma da Ciência da Informaçação ÉticaÉtica

Memória Redes Conceituais Értica

Linguagem Regime de Informação Mruivologia

Interdisciplinaridade

Fonte: Dados da pesquisa (2019).

O maior índice de pesquisa, considerando as 16 (dezesseis) categorias supracitadas no Quadro 2, foi campo científico da ciência da Informação, com 18 (dezoito) estudos que versam nesta categoria, como também pode ser observado no destaque da palavra-chave na Figura 2. Realçamos que julgamos relevante o campo científico remetendo a Bourdieu 
(2004) que retrata como mundo social que busca estabelecer os diferentes sujeitos caracterizados pelos pesquisadores que participam da estruturação desse campo, seja mantendo ou modificando sua estrutura. Portanto, esta categoria referência a estruturação do campo científico da Ciência da Informação.

Já na categoria da epistemologia em Ciência da Informação, as pesquisas apresentadas no GT1 do ENANCIB buscaram debater as teorias que envolvem a informação, seus desdobramentos e limites do conhecimento na Ciência da Informação, fazendo também alusão à filosofia e ciência, evidenciando os extratos de sua natureza, seu mecanismo e seu alcance.

Quanto à categoria ética, as comunicações analisadas se preocuparam com as questões híbridas em torno da ética da informação, caracterizando suas reflexões nas concepções sobre normas, valores e direito à informação na sociedade moderna.

Na categoria interdisciplinaridade, podemos remeter a Le Coadic (2004, p. 22), que epiloga a base conceitual da interdisciplinaridade como "[...] colaboração entre diversas disciplinas, que leva às interações, isto é, certa reciprocidade, de forma que haja, em suma, enriquecimento mútuo.". Portanto, verificamos que os estudos desta categoria, examinaram a disciplinaridade, interdisciplinaridade e transdisciplinaridade sobre diferentes interfaces.

Referente aos estudos da história em Ciência da Informação, as investigações tiveram uma abordagem histórica, cultural da Ciência da Informação, ou seja, as pesquisas estavam entrelaçadas com estudos de cunho históricos e metodológico.

Ao pautar sobre a categoria dos paradigmas da Ciência da Informação, as palavraschaves utilizadas nessa categoria, ou se direcionava ao termo em questão, ou sugerem teorias paradigmáticas como propostas de pesquisa para área.

$\mathrm{Na}$ diversidade de assuntos investigados nas comunicações, foi possível verificar a dinâmica que ocorre nos estudos do GT1 do ENANCIB, através de sua literatura especializada.

Com relação aos pesquisadores, foram identificados 25 (vinte e cinco) no total. Destes, 12 (doze) pesquisadores publicaram apenas um artigo, correspondendo a $48 \%$ do total, fato que se pode classificá-los como novatos nos estudos que envolvam os assuntos do GT1, por enquanto, com pouca contribuição efetiva. Os autores que publicaram mais de duas comunicações em edições diferente do ENANCIB são apresentados na Tabela 1.

TABELA 1 - Autores mais produtivos no GT1 dos Enancib (2014-2016)

\begin{tabular}{ll|ll}
\multicolumn{1}{c}{ Autores } & $\Sigma$ & \multicolumn{1}{|c}{ Autores } & $\Sigma$ \\
\hline GONZÁLEZ DE GOMEZ, M. N.(UFF) & 4 & FERNANDES, Geni C. (UNIRIO) & 2 \\
RODRIGUES, Georgete Medleg (UnB) & 4 & FONSECA, Vitor M. Marques (UFF) & 2 \\
SALDANHA, Gustavo S. (UNIRIO) & 4 & GUERRA, Claudia B. (UNIRIO) & 2 \\
FREIRE, Isa Maria (UFPB) & 3 & MARQUES, A. A. da Cunha (UnB) & 2 \\
SCHNEIDER, Marco A. F. (UFF) & 3 & PALETTA, Francisco Carlos (USP) & 2 \\
SOUZA, Edivanio Duarte de (UFAL) & 3 & PINHEIRO, Lena V. Ribeiro (IBICT) & 2 \\
SILVA, Jonathas L. Carvalho (UFCA) & 3 & RABELLO, Rodrigo (UnB) \\
SILVA, Zayr Cláudio G. da (UFPB) & 3 & & 2 \\
\hline
\end{tabular}

Fonte: Dados da pesquisa (2019).

A partir dos dados expostos, ressaltam-se os pesquisadores Maria Nélida González de Gómez (UFF), Gustavo Silva Saldanha (UNIRIO) e Georgete Medleg Rodrigues (UNB), que apresentam produções científicas em todas as edições do evento, além de colaborarem com publicações em parcerias com outros pesquisadores. 
Percebe-se, na Tabela 1, a existência de um grupo de 15 (quinze pesquisadores) (52\%) pesquisadores dedicados à temática do seleto grupo de trabalho de Estudos Históricos e Epistemológicos da Ciência da Informação (GT1), cujas publicações denotam que suas práticas de pesquisas são focadas e constantes na comunidade científica.

Ressalta-se o cuidado que área deve ter em salvaguardar para que não ocorra o "Efeito Mateus" na produção científica de seus pesquisadores, ou seja, segundo essa teoria os mais produtivos tendem a ser mais reconhecidos por acumularem um maior volume de capital científico e assim influenciam o estatuto científico da área (BOURDIEU, 2004).

Quadro 3 - Instituição dos pesquisadores que publicaram no GT1 do ENANCIB (2014-2016)

\begin{tabular}{|c|c|c|c|c|}
\hline \multirow{2}{*}{ Instituição } & \multicolumn{3}{|c|}{ Edição do Enancib } & \multirow{2}{*}{ Total } \\
\hline & 2014 & 2015 & 2016 & \\
\hline Universidade Federal da Paraíba (UFPB) & 2 & 3 & 2 & 7 \\
\hline 1. Universidade Federal de Alagoas (UFAL) & -- & 1 & 1 & 2 \\
\hline Universidade Federal da Bahia (UFBA) & 1 & 1 & -- & 2 \\
\hline UFCA Universidade Federal do Cariri (UFCA) & -- & 1 & 1 & 2 \\
\hline Universidade Federal do Ceará (UFC) & 1 & -- & - & 1 \\
\hline$\frac{{ }^{2}}{2}$ Universidade Federal de Pernambuco (UFPE) & 2 & -- & -- & 2 \\
\hline UnB Universidade de Brasília (UnB) & 4 & 1 & 4 & 9 \\
\hline $\begin{array}{l}\text { Universidade Federal Fluminense (UFF) | Yribict } \\
\text { Instituto Brasileiro de Informação em Ciência e Tecno- } \\
\text { logia (IBICT) }\end{array}$ & 4 & 3 & 3 & 10 \\
\hline $\begin{array}{l}\text { UN Univo Universidade Federal do Estado do Rio de Janeiro } \\
\text { (UNIRIO) }\end{array}$ & 3 & 1 & 3 & 7 \\
\hline $\begin{array}{l}\text { Quniversidade Federal do Rio de Janeiro (UFRJ) | } \\
\text { Yribict Instituto Brasileiro de Informação em Ciência e } \\
\text { Tecnologia (IBICT) }\end{array}$ & 1 & 1 & 7 & 9 \\
\hline T月S Universidade Federal do Espírito Santo (UFES) & -- & 1 & -- & 1 \\
\hline Universidade de São Paulo (USP) & 1 & 2 & 1 & 4 \\
\hline Universidade Federal Minas Gerais (UFMG) & -- & 1 & 2 & 3 \\
\hline ufkemen Universidade Federal de São Carlos (UFSCar) & -- & -- & 1 & 1 \\
\hline (1) Universidade Estadual de Londrina (UEL) & -- & 1 & -- & 1 \\
\hline $\begin{array}{l}\text { DUDESC Universidade do Estado de Santa Catarina } \\
\text { (UDESC) }\end{array}$ & -- & 1 & 1 & 2 \\
\hline (ப) Universidade Federal do Rio Grande (FURG) & 1 & -- & -- & 1 \\
\hline$\frac{1}{6}$ Universidade Federal de Santa Catarina (UFSC) & -- & -- & 2 & 2 \\
\hline $\begin{array}{l}\text { U.PORTO Universidade do Porto (Portugal) I parceria } \\
\text { com Universidade de São Paulo (USP) }\end{array}$ & -- & -- & 1 & 1 \\
\hline Total & & & & 67 \\
\hline
\end{tabular}

Fonte: Dados da pesquisa (2019).

\footnotetext{
${ }^{5}$ Efeito Mateus, é uma tese enunciada por Robert Merton (2013), que faz alusão ao evangelho de Mateus, ao se tratar de um fenômeno social que enfatiza os pesquisadores mais renomados tendem a receber mais reconhecimento e recursos financeiros por suas atividades acadêmicas, enquanto demais pesquisadores com pouco reconhecimento recebem menos créditos em suas atividades. Segundo o Evangelho de Mateus em seu capítulo 25, versículo 29: “A todo aquele que acredita mais fé Ihe será dada em abundância; e daquele que não crê lhe será tirado".
} 
Salienta-se que uma área só consegue conquistar um alto grau de institucionalização científica a partir do momento que seus pesquisadores socializam e compartilhem seu baluarte teórico e metodológico.

Com relação à vinculação institucional dos pesquisadores do GT1 presentes nos anais do ENANCIB, identificou-se um total de 19 (dezenove) instituições, dessas, seis instituições (31\%) tiveram apenas uma publicação no período analisado, conforme pode ser observado no Quadro 3.

Entre as instituições mais produtivas destacam-se a Universidade Federal Fluminense (UFF), em convênio com Instituto Brasileiro de Informação em Ciência e Tecnologia (IBICT), com dez (15\%) estudos publicados, a Universidade Federal do Rio de Janeiro (UFRJ), em convênio com IBICT, e Universidade de Brasília (UnB), ambas com nove publicações. A Universidade Federal da Paraíba (UFPB) e Universidade Federal do Estado do Rio de Janeiro (UNIRIO) publicaram sete trabalhos cada.

É prudente salientar que o interesse deste estudo concentrou-se nos dados de instituição de pesquisa, com base nas informações levantadas nos anais do GT1 do ENANCIB. Desta forma, ficou comprovado que as pesquisas no recorte das comunicações coletadas foram realizadas em instituições públicas, tanto de esfera federal como estadual, esta conforme pode ser percebido com a presença de pesquisadores da Universidade de São Paulo (USP) e Universidade do Estado de Santa Catarina (UDESC).

Também é importante destacar que a partir dos dados coletados, há a presença de uma única instituição estrangeira como participante do GT1, no período pesquisado, a Universidade do Porto, instituição de ensino superior pública de Portugal.

Destaca-se também o interesse das instituições de diversas localidades geográficas do Brasil, em debruçarem-se nas questões que envolvem o pensamento científico histórico e epistemológico no contexto da Ciência da Informação, especialmente, as instituições da região Sudeste com 35 (trinta e cinco) publicações (52\%), e região Nordeste com 16 (dezesseis) publicações (23\%) no GT1 do ENANCIB.

$\mathrm{O}$ aspecto enfatizado nesta pesquisa buscou contribuir para conhecer a realidade científica de um grupo temático, por meio de sua sociedade científica, como também, certificar a dinâmica e a relação existente entre assuntos, pesquisadores, instituições e constructos científicos da Ciência da Informação.

\section{CONSIDERAÇÕES FINAIS}

A partir da análise da produção científica apresentada no GT-1 do ENANCIB, nas edições de 2014, 2015 e 2016, foi possível observar que a consolidação dos estudos sobre a epistemologia da Ciência da Informação pode ser investigada em múltiplos enfoques.

Observa-se que o GT1 do ENANCIB representa parte do fórum que congrega pesquisadores que trazem à tona discussões de temas significativos para constituição teórica e epistemológica para Ciência da Informação, ressalvando que nenhum conhecimento está pronto e acabado, mas, ao contrário disso, deve estar sempre em processo de construção, mudando de acordo com as necessidades e críticas de sua comunidade científica.

Neste prisma, como a ciência está incumbida do processo de mudanças paradigmáticas, o GT1 como um mecanismo de divulgação da Ciência da Informação não fica à margem dessas mudanças. Além disso, também se verificou, entre outros aspectos, uma multiplicidade de assuntos nas comunicações do GT1, indo de encontro com o estatuto da Ciência da Informação. Os assuntos com maior incidência nas pesquisas foram os que dizem respeito à 
Ciência da Informação e as relações interdisciplinares com as demais áreas do conhecimento, destacando as diversas abordagens desse tema.

Neste estudo não foi realizado um acompanhamento das mudanças de concentração do GT-1 que permitisse observar as suas transformações no decorrer do tempo, porém, o quadro analisado apresentou uma multiplicidade de abordagens e abriga questões contemporâneas como, por exemplo, Arquivologia, linguagem e memória. É nessa perspectiva histórica e epistemológica que encaminhamos a refletir sobre a Ciência da Informação brasileira, seu estágio atual e tendências.

\section{REFERÊNCIAS}

ASSOCIAÇÃO NACIONAL DE PESQUISA E PÓS-GRADUAÇÃO EM CIÊNCIA DA INFORMAÇÃO ANCIB. 2019. Disponível em: http://www.ancib.org.br/. Acesso em: 08 ago. 2019.

ARAÚJO, C. A. Á. Ciência da Informação, Biblioteconomia, Arquivologia e Museologia: relações institucionais e teóricas. Encontros Bibli: Revista eletrônica de Biblioteconomia e Ciência da Informação, Florianópolis, v. 16, n. 31, p.110-130, 2011. Disponível em:

http://www.brapci.inf.br/ repositorio/2011/09/pdf e9d23645f2 0018712.pdf. Acesso em: 20 dez. 2019.

AZEVEDO, A. W. A construção da ciência da informação na pós-modernidade: dialética histórica. Revista Digital de Biblioteconomia e Ciência da Informação, Campinas, v.6, n.2, p. 7182, jan./jun. 2009. Disponível em:

https://periodicos.sbu.unicamp.br/ojs/index.php/rdbci/article/view/1989/2110. Acesso em: 20 dez. 2019.

BACHELARD, G. O novo espírito científico. São Paulo: Abril Cultural, 1978.

BAZI, R. E.R.; SILVEIRA, M. A. A. Constituição e institucionalização da ciência: apontamentos para uma discussão. TransInformação, Campinas, v. 19, n. 2, p. 129- 137, maio/ago. 2007. Disponível em: http://www.scielo.br/scielo.php?pid=S010337862007000200004\&script=sci abstract\&tlng=pt. Acesso em: 20 dez. 2019.

BORKO, H. Information science: What is it! American Documentation, v.19, n. 1, p. 3-5, jan. 1968.

BOURDIEU, P. Os usos sociais da ciência: por uma sociologia clínica do campo científico. São Paulo: Editora UNESP, 2004.

BRAMAN, S. The change of the State: information, policy, and power. Cambridge, MA: MIT, 2006.

BUSH, V. As we may think. Atlantic Monthly, v.176, 1, p.101-108, 1945. Disponível em: http://www.theatlantic.com/unbound/flashbks/computer/bushf.htm. Acesso em: 18 ago. 2019. 
CAPURRO, R. Epistemologia e ciência da informação. In: ENCONTRO NACIONAL DE PESQUISA EM ciência da informação, 5., 2003, Belo Horizonte. Anais [...] Belo Horizonte, UFMG, 2003. Disponível em: http://www.capurro.de/enancib p.htm. Acesso em: 12 ago. 2019.

FRANCELIN, M. M. Abordagens em epistemologia: Bachelard, Morin e a epistemologia da complexidade. TransInformação, Campinas, v.17, n.2, p. 101-109, maio/ago. 2005. Disponível em: http://www.brapci.inf.br/index.php/article/download/6081. Acesso em: 12 ago. 2019.

FREIRE, I. M. Um olhar sobre a produção científica brasileira na temática epistemologia da Ciência da Informação. Tendências da Pesquisa Brasileira em Ciência da Informação, v.1, n.1. 2008. Disponível em: http://www.brapci.inf.br/index.php/article/download/6884. Acesso em: 20 dez. 2019.

GODOY, A. A. Estudo de caso qualitativo. In: GODOI, C.K.; MELO, R.; SILVA, A. B. (Org.). Pesquisa qualitativa em estudos organizacionais: paradigmas, estratégias e métodos. São Paulo: Saraiva, 2006. p.115-146.

JAPIASSU, H. Introdução ao pensamento epistemológico. 4.ed. Rio de Janeiro: Francisco Alves Editora, 1986.

HJØRLAND, B. Theory and metatheory in Information Science: a new interpretation. Journal of Documentation, v. 54, n. 5, p. 606-621, dez. 1998.

KOBASHI, N. Y.; TÁLAMO, M. F. G. Informação: fenômeno e objeto de estudo da sociedade contemporânea. TransInformação, v. 15, edição especial, p. 7-21, set./dez. 2003. Disponível em: http://www.scielo.br/pdf/tinf/v15nspe/01.pdf. 20 dez. 2019.

KUHN, T. S. A estrutura das revoluções científicas. 9. ed. São Paulo: Perspectiva, 2005.

LE COADIC, Y. F. A Ciência da Informação. Brasília: Brinquet Lemos, 2004.

MATTELART, A. História da utopia planetária: da cidade profética à sociedade global. Porto Alegre: Ed. Sulina, 2002.

MERTON, R. K. Ensaios de sociologia da ciência. São Paulo: Editora 34, 2013.

MINAYO, M.C. S. O desafio do conhecimento: pesquisa qualitativa em saúde. São Paulo: Hucitec, 2007.

MORIN, E. O problema epistemológico da complexidade. 2. ed. Portugal: Europa-America, 1996.

NUNES, L. Epistemologia e Ciência da Informação: um estudo das comunicações do GT1 do ENANCIB. 2009. 132f. Dissertação (Mestrado em Ciência da Informação) - Faculdade de Filosofia e Ciências, Universidade Estadual Paulista "Júlio de Mesquita Filho", Marilia/SP. 2009. 
ORTEGA, C. D. A documentação como origem e base fértil para a fundamentação da Ciência da Informação. In: ENCONTRO NACIONAL DE PESQUISA EM CIÊNCIA DA INFORMAÇÃO, 2007, 8., Salvador. Anais eletrônicos [...] Salvador: UFBA, 2007.

PINHEIRO, L. V. R. Gênese da Ciência da Informação ou sinais anunciadores da nova área. In: O campo da Ciência da Informação: gênese, conexões e especificidades. João Pessoa, UFPB, 2002, p. 61-86.

POPPER, K. Conhecimento objetivo: uma abordagem evolucionária. Belo Horizonte: Itatiaia/São Paulo: Edusp, 1975.

RAYWARD, W.B. The origins of Information Science and the International Institute of Bibliography/International Federation for Information and Documentation (FID). Journal of the American Society for Information Science, v.48, n.4, p.289-300, 1997.

SARACEVIC, T. A natureza interdisciplinar da ciência da informação. Ciência da Informação, Brasília, v. 24, n. 1, p. 36-41, 1995. Disponível em:

http://revista.ibict.br/ciinf/article/view/608/610. Acesso em: 20 dez. 2019.

SHERA, J.; CLEVELAND, D. History and foundations of information science. Annual Review of Information Science and Technology, Washington, v. 12, p. 249-275, 1977.

SHERA, J. H. Sobre Biblioteconomia, Documentação e Ciência da Informação. In: FOSKETT, D. J. (Org.). Ciência da Informação ou Informática? Trad. de Hagar Espanha Gomes. Rio de Janeiro: Calunga, 1980.

SMIT, J. W.; TÁLAMO, M. F. G. M. Ciência da Informação: pensamento informacional e integração disciplinar. Brazilian Journal of Information Science, v. 1, n. 1, jan./jun. 2007. Disponível em: http://www2.marilia.unesp.br/revistas/index.php/bjis/article/view/30/29. Acesso em: 20 dez. 2019.

SOUZA, E. D. A institucionalização da ciência da Informação no Brasil: elementos disciplinadores do campo científico. Informação e Sociedade: Estudos, João Pessoa, v.22, p. 49- 64, n. especial, 2012. Disponível em:

https://periodicos.ufpb.br/ojs/index.php/ies/article/view/13297/8568. Acesso em: 20 dez. 2019.

TOFFLER, A. A terceira onda: a morte do industrialismo e o nascimento de uma nova civilização. Trad. João Tavora. 32. ed. Rio de Janeiro: Record, 2014.

WERSIG, G. Information science: the study of postmodern knowledge usage. Information Processing \& Management, v. 29, n. 2, p. 229-239, 1993. 